\title{
ESTIMASI SEBARAN HIDROKARBON DENGAN MENGGUNAKAN INDIKATOR P-WAVE DIFFERENCE DISPERSION FACTOR PADA LAPANGAN BONAPARTE
}

\author{
Mokhammad Puput Erlangga ${ }^{*}$, Handoyo $^{2}$, Egie Wijaksono $^{3}$ \\ ${ }^{1,2}$ Teknik Geofisika Institut Teknologi Sumatera; Jalan Terusan Ryacudu, Desa Way Hui, Jati \\ Agung, Lampung Selatan 35365, (0721) 8030188/pusat@itera.ac.id \\ ${ }^{3}$ Pusat Penelitian dan Pengembangan Teknologi Minyak dan Gas Bumi; Jalan Ciledug Raya \\ Kav.109, Cipulir, Kebayoran Lama, Jakarta Selatan 12230, (021) 7394422, 7394778 Ext \\ 1212, 1226 Fax (021) 7246150/http://www.lemigas.esdm.go.id
}

Corresponding author: mokhammad.erlangga@tg.itera.ac.id

Manuscript received: July 22, 2019; revised: August 9, 2019;

Approved: August 22, 2019; available online: November 11, 2019

\begin{abstract}
Abstrak - Pada eksplorasi hidrokarbon, kita membutuhkan suatu indikator yang menunjukkan keberadaan hidrokarbon secara akurat. Maka dari itu, dengan menggunakan indikator tersebut, kita dapat melihat sebaran serta dimensi dari reservoar hidrokarbon dengan lebih baik. Indikator yang digunakan pada penelitian kali ini adalah Faktor Dispersi Perubahan Kecepatan Gelombang P. Indikator ini akan melihat seberapa besar perubahan kecepatan gelombang $\mathrm{P}$ terhadap frekuensi. Pada media yang berpori dan tersaturasi gas, kecepatan gelombang $\mathrm{P}$ akan mengalami penurunan terhadap frekuensi yang disebabkan karena adanya atenuasi. Sehingga Faktor Dispersinya akan sangat bernilai negatif. Maka dari itu nilai Faktor Dispersi Perubahan Kecepatan Gelombang P sangat dipengaruhi oleh keberadaan gas pada pori batuan. Prediksi sebaran gas dengan menggunakan indikator Faktor Dispersi Perubahan Kecepatan Gelombang menunjukkan hasil akurat pada daerah yang terdapat sumur eksplorasi, dimana pada daerah tersebut menunjukkan keberadaan gas sesuai dengan apa yang diperlihatkan oleh data sumur. Maka dari itu, indikator Faktor Dispersi Perubahan Kecepatan Gelombang P merupakan indikator yang sensitif untuk melihat keberadaan hidrokarbon yang berupa gas.
\end{abstract}

\begin{abstract}
In hydrocarbon exploration, we need an indicator that shows the presence of hydrocarbons accurately. Therefore, using the indicator, we can better see the distribution and dimensions of the hydrocarbon reservoir. The indicator used in this study is the P-Wave Difference Dispersion Factor. This indicator will see how much the P wave velocity changes with frequency. In porous and gas saturated media, the $\mathrm{P}$ wave velocity will decrease with frequency caused by attenuation. So the Dispersion Factor will be very negative. Therefore the value of P-Wave Difference Dispersion Factor is strongly influenced by the presence of gas in the rock pore. Gas distribution prediction using the P-Wave Difference Dispersion Factor shows accurate results in the area where there are exploration wells, which in the area indicate the presence of gas according to what is shown by the well data. Therefore, the indicator of P-Wave Difference Dispersion Factor are sensitive to the presence of hydrocarbon in the form of gas.
\end{abstract}

Keywords: Dispersion, frequency, velocity, $P D D F$

How to cite this article:

Erlangga, M.P., Handoyo, dan Wijaksono, E., 2019, Estimasi Sebaran Hidrokarbon dengan Menggunakan Indikator P-Wave Difference Dispersion Factor Pada Lapangan Bonaparte, Jurnal Geofisika Eksplorasi, 5 (3) p.204-213. doi: 10.23960/jge.v5i3.35 


\section{PENDAhuluan}

Gelombang seismik yang merambat melalui medium batuan yang tersaturasi oleh fluida (hidrokarbon) akan mengalami atenuasi yang cukup kuat dan dispersi gelombang. Atenuasi gelombang seismik diakibatkan oleh disipasi energi gelombang seismik sebagai akibat adanya gesekan antara matrik batuan dengan fluida yang tersaturasi pada pori batuan saat gelombang melalui medium tersebut. Sehingga atribut gelombang seismik seperti amplitudo dan frekuensi gelombang akan mengalami penurunan nilai (Castagna, 2003). Sedangkan dispersi adalah perubahan nilai kecepatan gelombang seismik karena adanya perubahan nilai frekuensi gelombang seismik tersebut.

Teknik AVO yang digunakan selama ini (Aki, 1980; Shuey, 1985; Smith and Gidlow, 1987; Russell, 1991) semuanya mengasumsikan bahwa medium yang dialaui oleh gelombang seismik bersifat homogen. Seluruh parameter petrofisika seperti impedansi akustik, impedansi elastik, dan poisson's ratio diturunkan berdasarkan linearisasi persamaan Zoeppritz. Sehingga pengaruh perubahan atribut frekuensi dari data seismik tidak dapat diketahui.

Maka dari itu, pada penelitian kali ini kita akan menganalisis pengaruh frekuensi terhadap nilai properti petrofisika. Properti petrofisika yang akan digunakan dalam penelitian ini adalah kecepatan gelombang seismik. Analisis perubahan kecepatan sebagai fungsi frekuensi sangat berperan sebagai indikator langsung keberadaan fluida (hidrokarbon) yang tersaturasi di dalam pori batuan. Metode yang digunakan dalam penelitian ini disebut sebagai $P$ Wave Difference Dispersion Factor (PPDF). Dengan memperhatikan pengaruh frekuensi terhadap nilai kecepatan maka diharapkan metode $P$-Wave Difference Dispersion Factor (PPDF) ini dapat mendeliniasi keberadaan zona hidrokarbon lebih akurat.

\section{MODIFIKASI PERSAMAAN SMITH DAN GIDLOW}

Batzle dkk (2006) memperkenalkan bahwa batuan yang tersaturasi fluida memiliki properti petrofisika yang nilainya dipengaruhi oleh bandwith frekuensi gelombang seismik. Chapman dkk (2006) mendiskusikan secara teoretis implikasi dari AVO terhadap frekuensi. Wilson (2010) melihat kemungkinan adanya pendeteksian fluida yang berhubungan dengan dispersi dengan cara menggabungkan analisis AVO dengan dekomposisi spectral, dan menurunkan sebuah istilah baru yang disebut dispersi reflektivitas yang dapat mengkuantifikasi inversi reflektifitas yang dipengaruhi oleh frekuensi. Bagaimanapun juga, akurasi dari indikator ini dipengaruhi oleh teknik dekomposisi spectral, dan sensitif terhadap noise random.

Wilson (2010) mengembangkan aproksimasi dua suku AVO dengan menghitung dispersi kecepatan dan menampilkan bagaimana koefisien frekuensi dapat dipengaruhi oleh frekuensi. Aproksimasi AVO oleh Smith dan Gidlow dapat diperluas menjadi fungsi frekuensi.

$R\left(\theta_{i}, f_{j}\right) \approx A\left(\theta_{i}\right) \frac{\Delta V_{P}}{V_{P}}\left(f_{j}\right)+B\left(\theta_{i}\right) \frac{\Delta V_{S}}{V_{S}}\left(f_{j}\right)$

Dimana, $\theta$ adalah sudut datang, A dan $B$ adalah parameter-parameter yang berhubungan dengan $\theta$, yang dapat diekspresikan sebagai berikut.

$$
\begin{aligned}
& A(\theta)=\frac{5}{8}-\frac{1}{2} \frac{V_{S}^{2}}{V_{P}{ }^{2}} \sin ^{2} \theta+\frac{1}{2} \tan ^{2} \theta \\
& B(\theta)=4 \frac{V_{S}}{V_{P}{ }^{2}} \sin ^{2} \theta
\end{aligned}
$$

Selain itu, asumsikan A dan B tidak berubah terhadap dispersi kecepatan. Kemudian, kita dapat ekspansikan $A(\theta)$ dan $B(\theta)$ sebagai sebuah deret Taylor di sekitar frekuensi dominan $f_{0}$.

$$
\begin{aligned}
R\left(\theta_{i}, f_{j}\right) \approx & A\left(\theta_{i}\right) \frac{\Delta V_{P}}{V_{P}}\left(f_{0}\right)+\left(f_{j}-\right. \\
& \left.f_{0}\right) A\left(\theta_{i}\right) I_{a}+B\left(\theta_{i}\right) \frac{\Delta V_{S}}{V_{S}}\left(f_{0}\right)+ \\
& \left(f_{j}-f_{0}\right) B\left(\theta_{i}\right) I_{b}
\end{aligned}
$$


Dimana, $I_{a}$ dan $I_{b}$ adalah suku baru sebagai dispersi reflektivitas yang telah diperkenalkan oleh Wilson, yaitu:

$I_{a}=\frac{d}{d f}\left(\left|\frac{\Delta V_{P}}{V_{P}}\right|\right), I_{b}=\frac{d}{d f}\left(\left|\frac{\Delta V_{S}}{V_{S}}\right|\right)$

Akhirnya, berdasarkan pada teknik dekomposisi waktu-frekuensi dan metode spectrum balanced, persamaan matrik akhir dapat kita peroleh, dimana dapat kita sederhanakan menjadi:

$E=R\left[\begin{array}{l}I_{a} \\ I_{b}\end{array}\right]$

Persamaan di atas dapat kita selesaikan dengan inversi least square untuk setiap sampel waktu.

Kita asumsikan bahwa $V_{P 1}$ merupakan kecepatan gelombang $\mathrm{P}$ pada medium overburden shale tanpa disperse, dan $V_{P 2}$ merupakan keceptan gelombang $\mathrm{P}$ pada batuan yang tersaturasi gas, dan nilainya dipengaruhi oleh frekuensi sehingga menyebabkan dispersi kecepatan. Oleh karena itu:

$$
V_{P}(f)=\frac{V_{P 1}+V_{P 2}(f)}{2}, \Delta V_{P}(f)=V_{P 2}(f)-V_{P 1}
$$

Maka besarnya nilai PDDF adalah

$\mathrm{PPDF}=\Delta V_{P} \cdot I_{a}$

\section{DATA BONAPARTE}

\subsection{Geologi Regional}

Data yang digunakan pada penelitian ini adalah data lapangan Bonaparte yang terdiri dari data sumur dan data seismik post-stack 3D.

Cekungan Bonaparte terdapat di sebelah utara dari benua Australia dan tepat di selatan Nusa Tenggara Timur Indonesia (Gambar 1).

Terjadinya struktur cekungan Bonaparte (Barret dkk., 2004) meliputi:

a. Late Jurassic sampai awal Cretaceous terjadi struktur pengangkatan patahan.

b. Cretaceous dan Neogene pengaktifan kembali (Reactivation) di bawah oblique, left lateral, strongly strike - slip domain. c. Miocene Precent day, patahan esktensional (extensional faulting) signifikan Stike -slip assosiasi dengan palung Timor bagian utara Malita Graben sampai selatan.

d. Rift, pengankatan terkait dengan patahan selama akhir Jurassic sampai awal Createceous, trend Timor sampai barat adanya patahan dari northeast sampai southeast.

\subsection{Data Sumur}

Data sumur yang digunakan dalam penelitian ini terdiri dari dari empat data sumur, yaitu MKS-1, MKS-2, MKS-3, dan MKS-4. Pada setiap data sumur terdapat $\log$ kecepatan gelombang seismik $\mathrm{P}, \quad \log$ densitas, log sinar gamma, log neutron porosity, dan $\log$ resistivitas. Selain data $\log$, pada setiap sumur juga terdapat data marker untuk setiap formasi. Data marker yang digunakan dalam penelitian ini adalah TOP_RES, dimana marker tersebut menunjukkan formasi batuan pasir. Data $\log$ sumur tersebut dapat kita lihat pada Gambar 2.

Keberadaan batuan pasir pada formasi TOP_RES ditunjukkan dengan nilai log Gamma Ray yang rendah. Cut Off nilai Gamma Ray yang menunjukkan batuan pasir adalah kurang dari 60 API.

Berdasarkan hasil cross over antara log densitas dan log neutron porosity, maka kita dapat melihat adanya zona yang tersaturasi gas pada setiap sumur. Zona yang tersaturasi gas akan memiliki jarak pisah antara log densitas dan log neutron porosity. Selain itu, keberadaan zona yang tersaturasi gas dapat dilihat berdasarkan data $\log$ resistivitas, dimana pada daerah tersebut akan memiliki nilai resistivitas yang tinggi.

\subsection{Data Seismik}

Data seismik yang digunakan adalah data seismik 3D post-stack pada lapangan Bonaparte, dengan parameter akuisisi sample rate $4 \mathrm{~ms}$ dan record lama perekaman $5000 \mathrm{~ms}$, dengan luas area 84,4 $\mathrm{km}$ persegi. Tampilan data seismik $3 \mathrm{D}$ yang 
digunakan dalam penelitian ini dapat dilihat pada Gambar 3.

\section{METODOLOGI PENELITIAN}

\subsection{Pemrosesan Data}

Penelitian ini dilakukan dengan bantuan perangkat lunak Humpson Russel Software dan Petrel. Tahapan pertama pengolahan data yang dilakukan adalah korelasi data sumur terhadap data seismik. Langkah kedua adalah picking / interpretasi horizon Litologi pada data seismik. Langkah ketiga adalah membuat model awal impedansi akustik. Langkah keempat adalah melakukan inversi data seismik 3D untuk menghasilkan volume impedansi akustik yang kemudian transformasi untuk mendapatkan volume kecepatan gelombang $\mathrm{P}$ dengan menggunakan persamaan Gardner. Langkah kelima adalah menghasilkan atribut frekuensi dari data seismik. Langkah keenam adalah menghitung perubahan kecepatan terhadap perubahan frekuensi. Dan yang terakhir adalah menghitung nilai PDDF dan distribusinya pada horizon TOP_RES. Diagram alir pemrosesan data dapat dilihat pada Gambar 4.

\subsection{Interpretasi dan analisis}

Hasil inversi berdasarkan model awal dan perhitungan dengan persamaan 7 ini berupa sebaran nilai PDDF di bawah permukaan. Nilai PDDF ini dapat kita gunakan sebagai indikator keberadaan hidrokarbon pada lapisan formasi batuan pasir TOP_RES. Berdasarkan hasil yang kita peroleh maka kita dapat melihat estimasi sebaran hidrokarbon (gas) pada formasi TOP_RES.

\section{HASIL DAN PEMBAHASAN}

Berdasarkan hasil perhitungan atribut kecepatan dan frekuensi dengan menggunakan persamaan 7 maka kita dapat memperoleh besaran PDDF ( $P$-wave
Different Dispersion Factor) yang kita gunakan sebagai indikator keberadaan hidrokarbon. Hasil penampang 2D dari besaran PDDF dapat kita lihat pada Gambar 5 .

Berdasarkan Gambar 5a kita dapat melihat bahwa zona yang berwarna merah adalah daerah yang memiliki nilai PDDF negatif. PDDF yang bernilai negatif berasosiasi dengan adanya indikasi penurunan nilai kecepatan yang disertai dengan pelemahan nilai frekuensi gelombang seismik karena gelombang seismik tersebut teratenuasi saat melalui medium berpori yang tersaturasi oleh fluida.

Zona yang berwarna merah tersebut banyak terdapat pada closure di bagian tenggara, dimana semua sumur (MKS-1, MKS-2, MKS-3, MKS-4) berada di atas closure tersebut (Gambar 5b).

Distribusi nilai PDDF tersebut sesuai dengan konsep migrasi hidrokarbon, dimana hidrokarbon akan bermigrasi dari daerah yang memiliki tekanan dan temperatur tinggi (basin / cekungan) menuju daerah yang memiliki tekanan dan temperatur rendah (tinggian / antiklin) melalui pori batuan. Pada daerah antiklin banyak terdapat spot merah, dimana spot tersebut mengindikasikan keberadaan hidrokarbon (gas). Hal tersebut dapat dilihat pada Gambar 5c.

\section{KESIMPULAN}

\subsection{Kesimpulan}

Dari hasil penelitian yang dilakukan, maka dapat disimpulkan:

1. Indikator hidrokarbon PDDF merupakan indikator yang sensitif terhadap keberadaan fluida di dalam pori batuan karena gelombang seismik akan mengalami atenuasi dan dispersi ketika melewati medium berpori dengan saturasi fluida.

2. Hasil pada penelitian ini menunjukan bahwa distribusi nilai PDDF memiliki tren yang sama dengan distribusi 
hidrokarbon ketika mengalami jebakan struktur di dalam batuan reservoir, yaitu terdistribusi pada struktur antiklin.

3. Keberadaan fluida (gas) yang ditunjukkan oleh data sumur ternyata sesuai dengan prediksi daerah potensial fluida (gas) berdasarkan nilai PDDF pada titik lokasi sumur.

4. Daerah yang mengandung fluida (gas) akan memiliki nilai indikator PDDF negatif. Hal tersebut disebabkan karena adanya penurunan nilai kecepatan dan frekuensi gelombang seismik.

\section{UCAPAN TERIMA KASIH}

Terimakasih kepada Kementerian Riset dan Pendidikan Tinggi sebagai pihak pendanaan pada penelitian ini.

\section{DAFTAR PUSTAKA}

Aki, K. and Richards, P.G., 1980. Quantitative Seismology. W.H. Freeman and Co.

Barrett, A.G., Hinde, A.L. and Kennard, J.M., 2004. Undiscovered resource assessment methodologies and application to the Bonaparte Basin. In: Ellis, G.K., Baillie, P.W. and Munson, T.J. (eds), Timor Sea Petroleum Geoscience: Proceedings of the Timor Sea Symposium, Darwin, 19-20 June 2003. Northern Territory Geological Survey, Special Publication 1, 353372.

Batzle, M., R. Hofmann, D. H. Han, and J. P. Castagna. 2001. Fluids and frequency dependent seismic velocity of rocks. The Leading Edge 20: 168171.

Cadman, S.J., 2003. Bonaparte Basin, NT, WA, AC \& JPDA. Australia Petroleum Accumulations Report 5, 2nd Edition. Geoscience Australia, Canberra.
Castagna, J. P., S. Sun, and R. W. Siegfried. 2003. Instantaneous spectral analysis: Detection of low frequency shadows associated with hydrocarbons. The Leading Edge 22: 120-127.

Chapman, M., E. Liu, and X. Y. Li, 2005. The influence of abnormally high reservoir attenuation on the AVO signature. The Leading Edge 24: 1120 1125 .

Mory, A.J., 1988. Regional Geology of The Offshore Bonaparte Basin. In: Purcell, P.G. and Purcell, R.R.(eds), The North West Shelf Australia, Proceedings of Petroleum Exploration Society of Australia Symposium, Perth, 1988, 287-309.

Russell, B. H., 1991. Introduction to Seismic Inversion Methods. S. N. Domenico. Editor Course Notes Series, Volume 2nd Edition.

Smith, G.C. and Gidlow, P.M. 1987. Weighted stacking for rock property estimation and detection of gas. Geophysical Prospecting 35: $993-$ 1014.

Wilson, A., M. Chapman, and X. Y. Li. 2009. Frequency-dependent AVO inversion. Paper presented in 79th Annual International Meeting SEG. 2530 October 2009. Houston, Texas, USA.

Wilson, A. 2010. Theory and Methods of Frequency-Dependent AVO Inversion. Ph.D dissertation University of Edinburgh. 


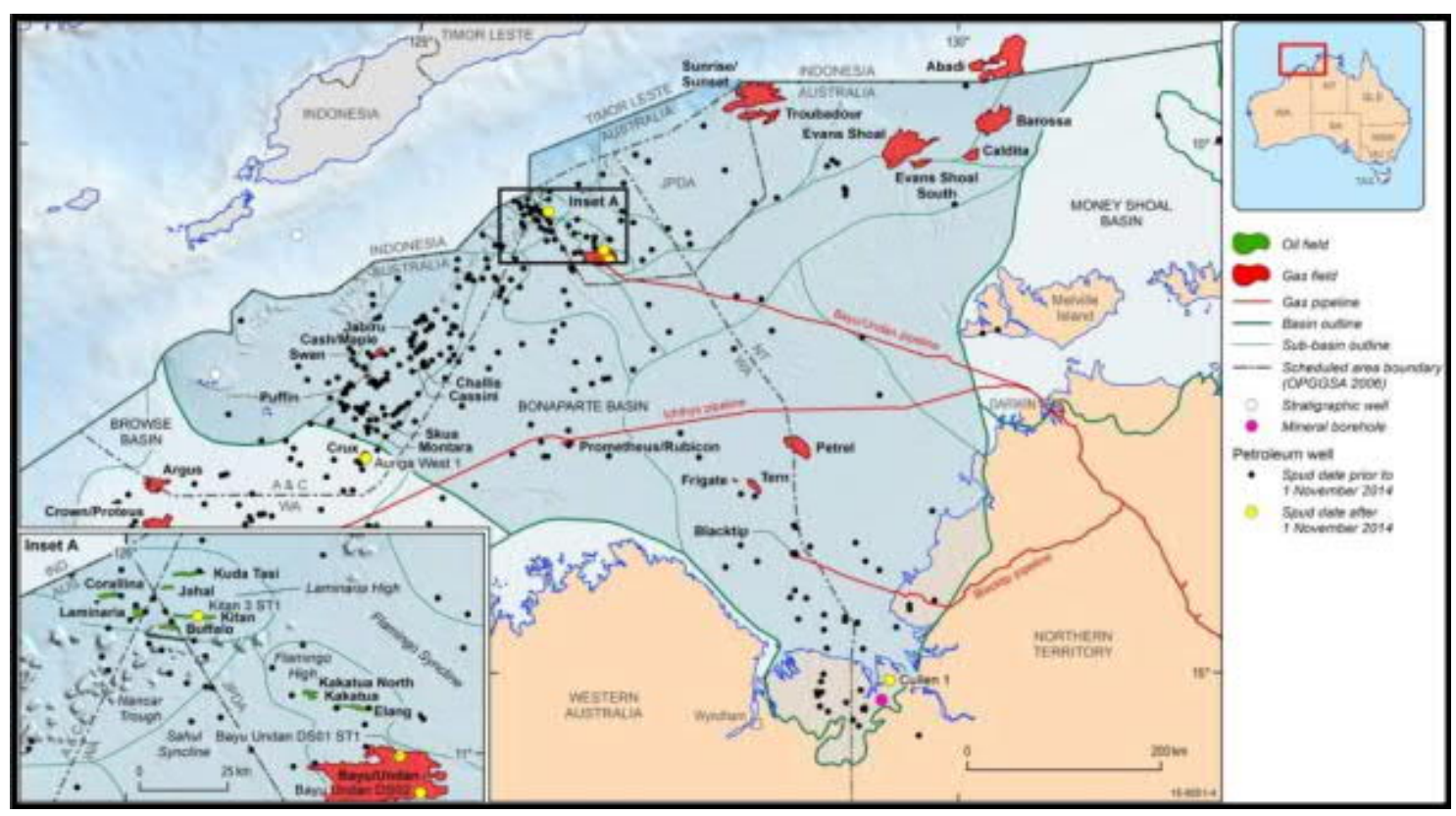

(a)

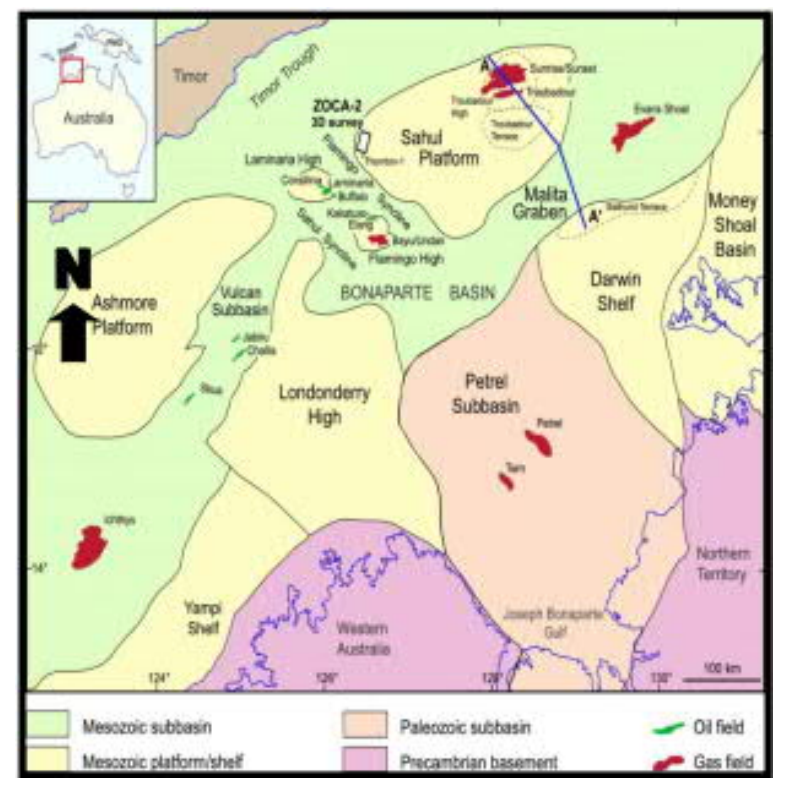

(b)

Gambar 1. (a) Daerah cekungan Bonaparte (Cadman, 2003), (b) tektonik cekungan Bonaparte (Mory, 1988) 


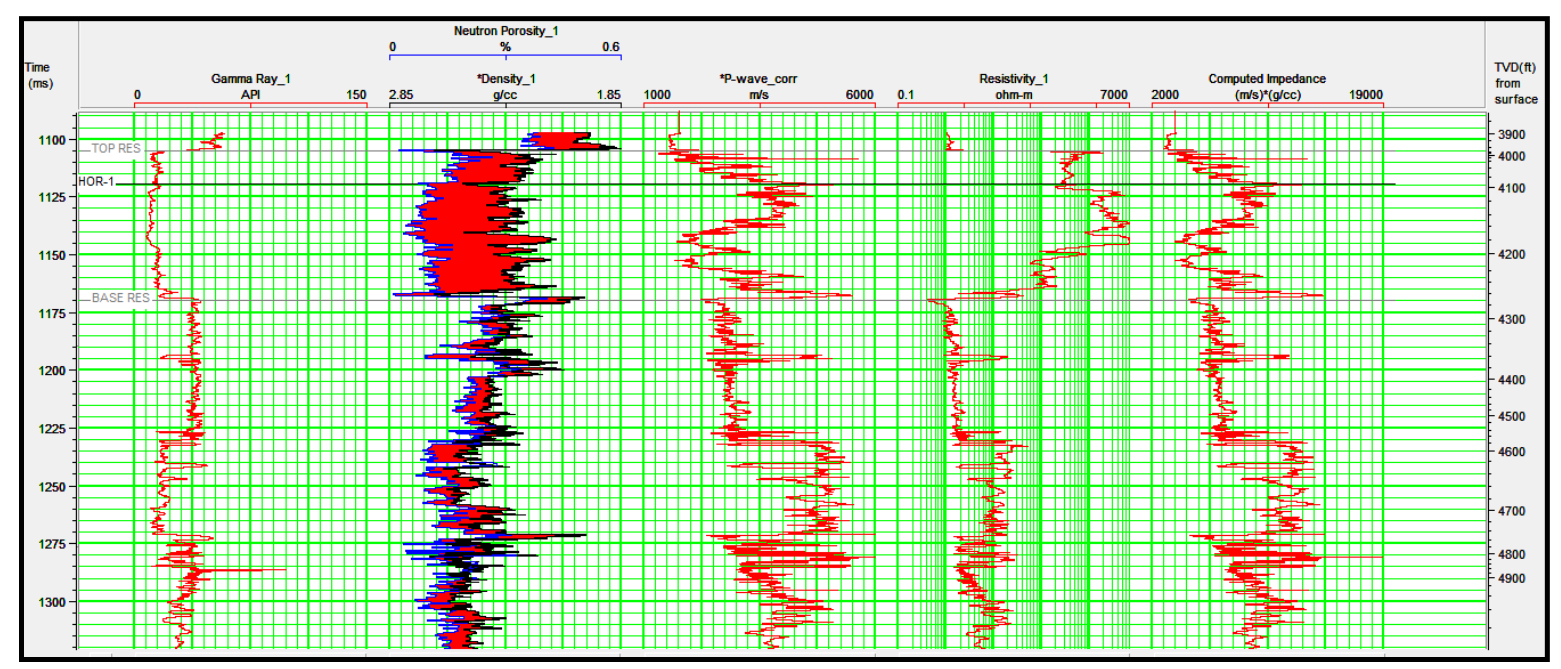

(a)

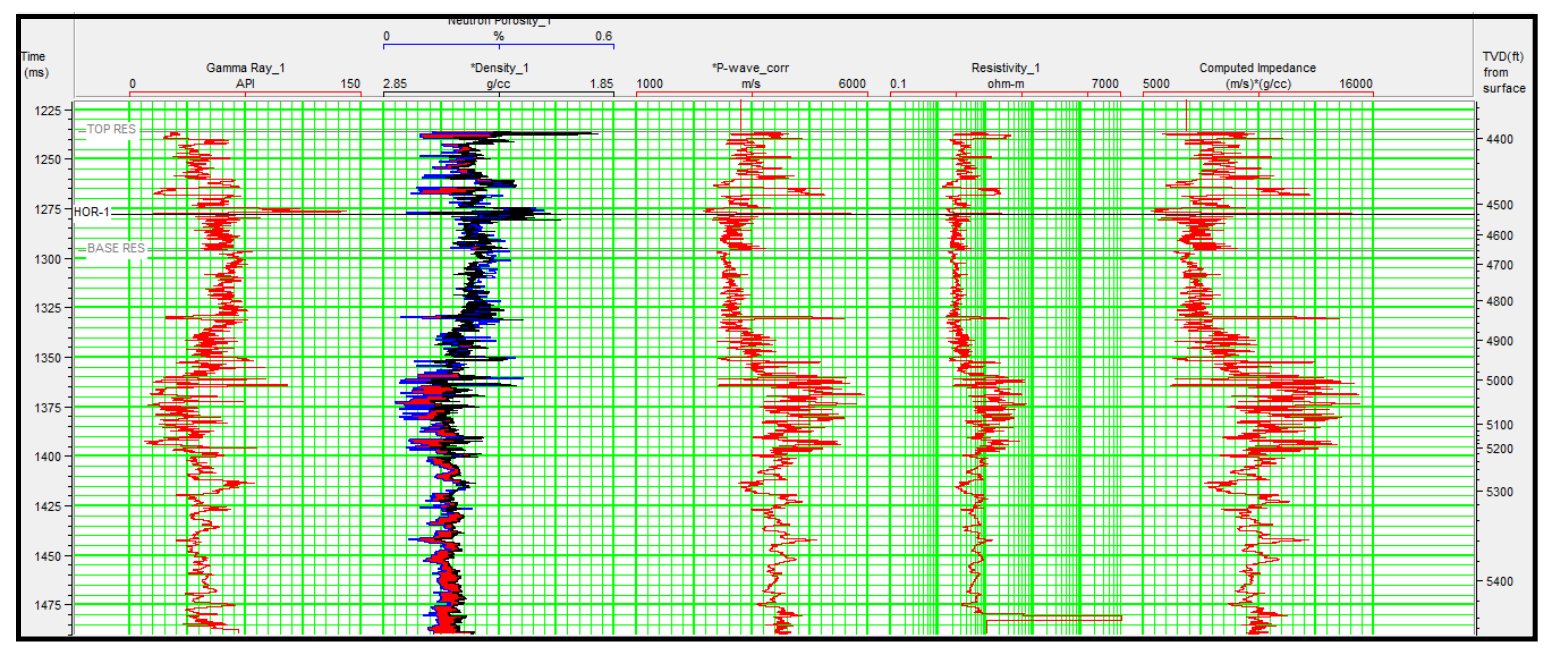

(b)

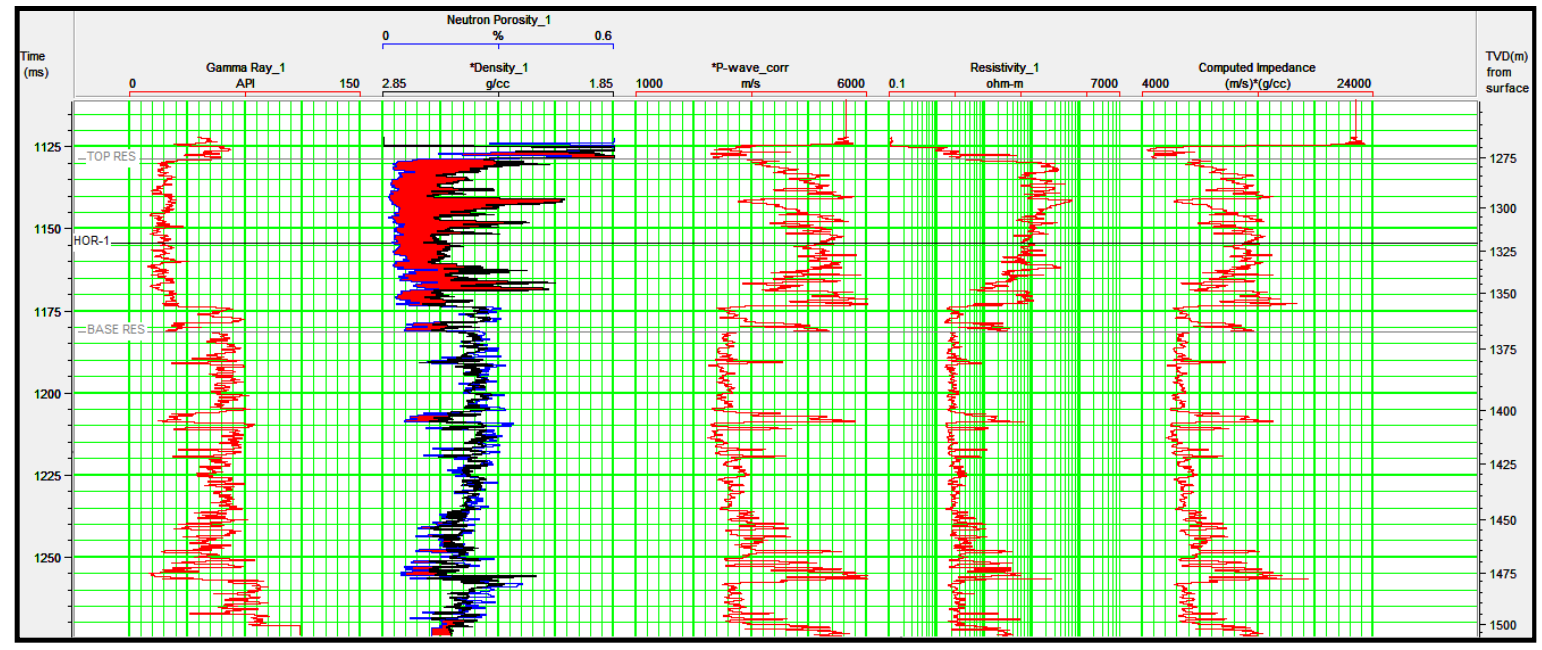

(c) 


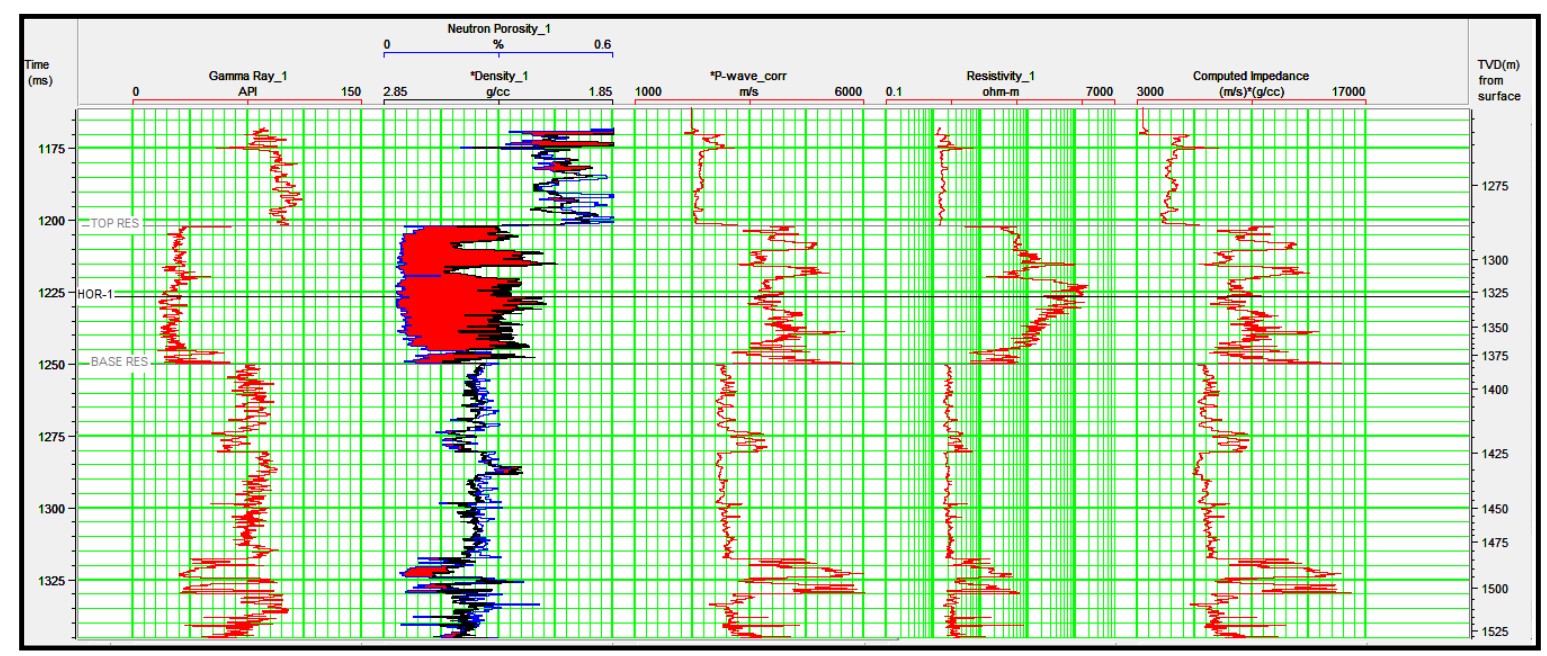

(d)

Gambar 2. Data log sumur (a) MKS-1, (b) MKS-2, (c) MKS-3, dan (d) MKS-4

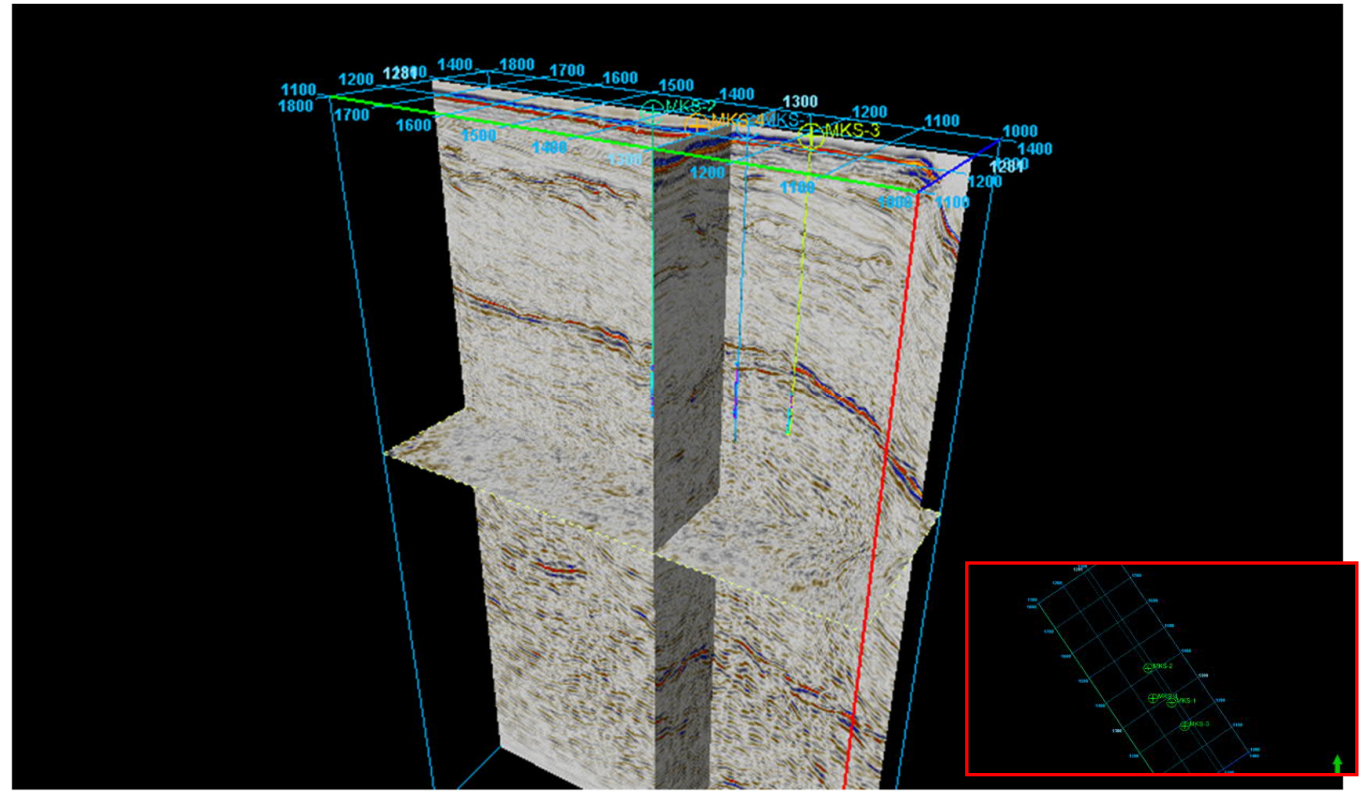

Gambar 3. Data Seismik post stack 3D dengan 4 sumur. 


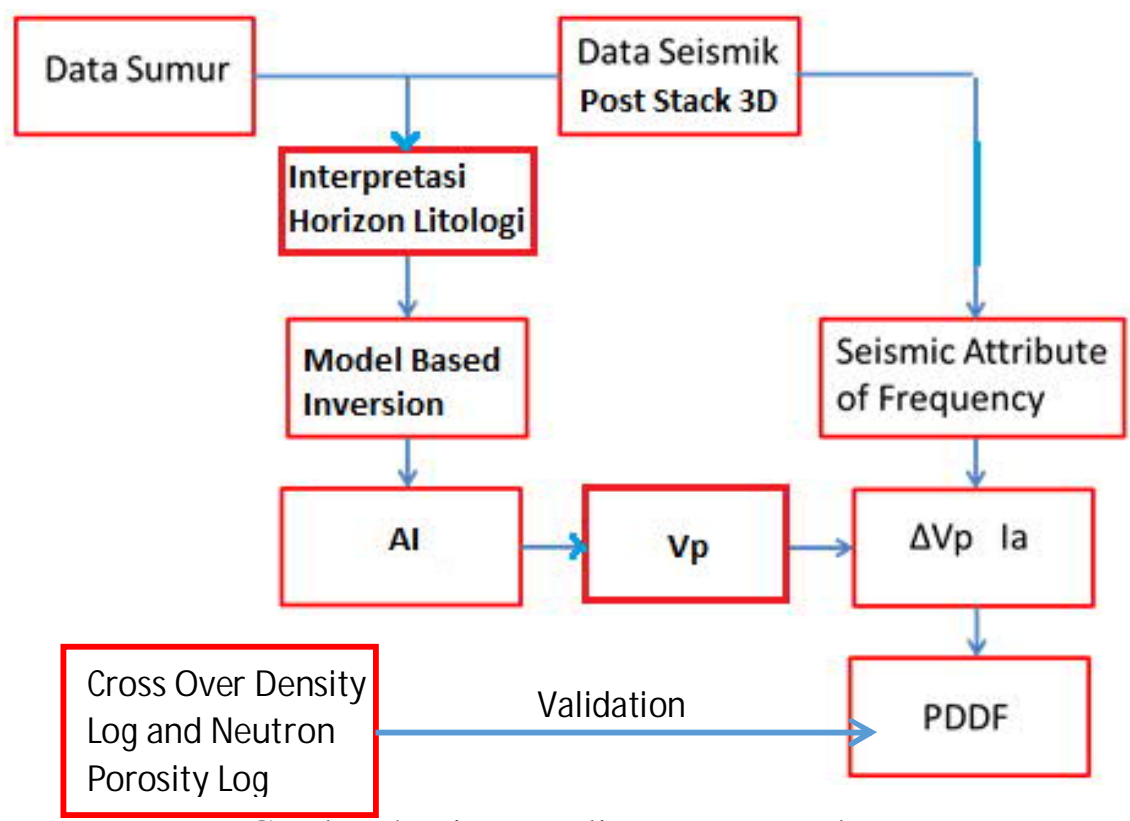

Gambar 4. Diagram alir pemrosesan data

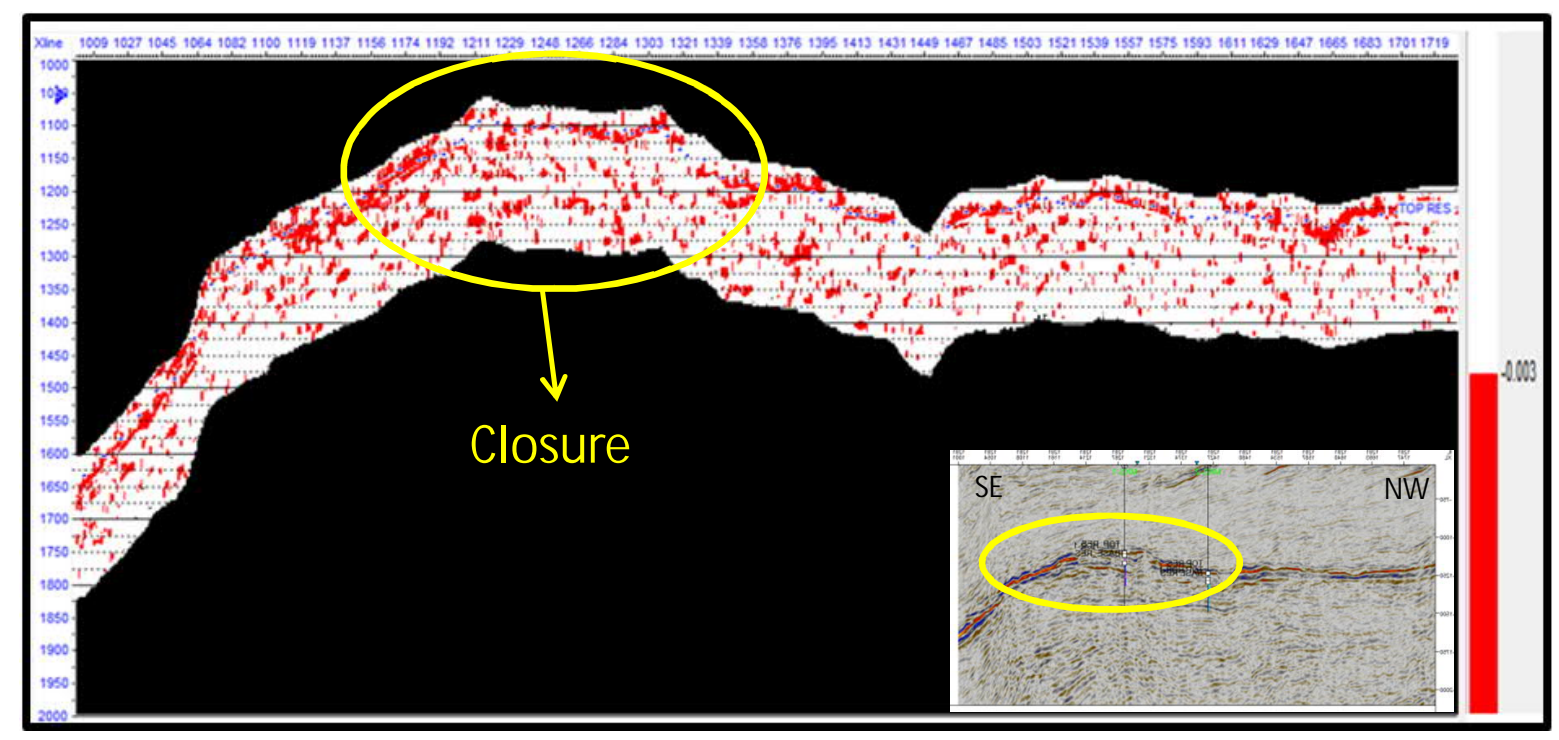

(a) 


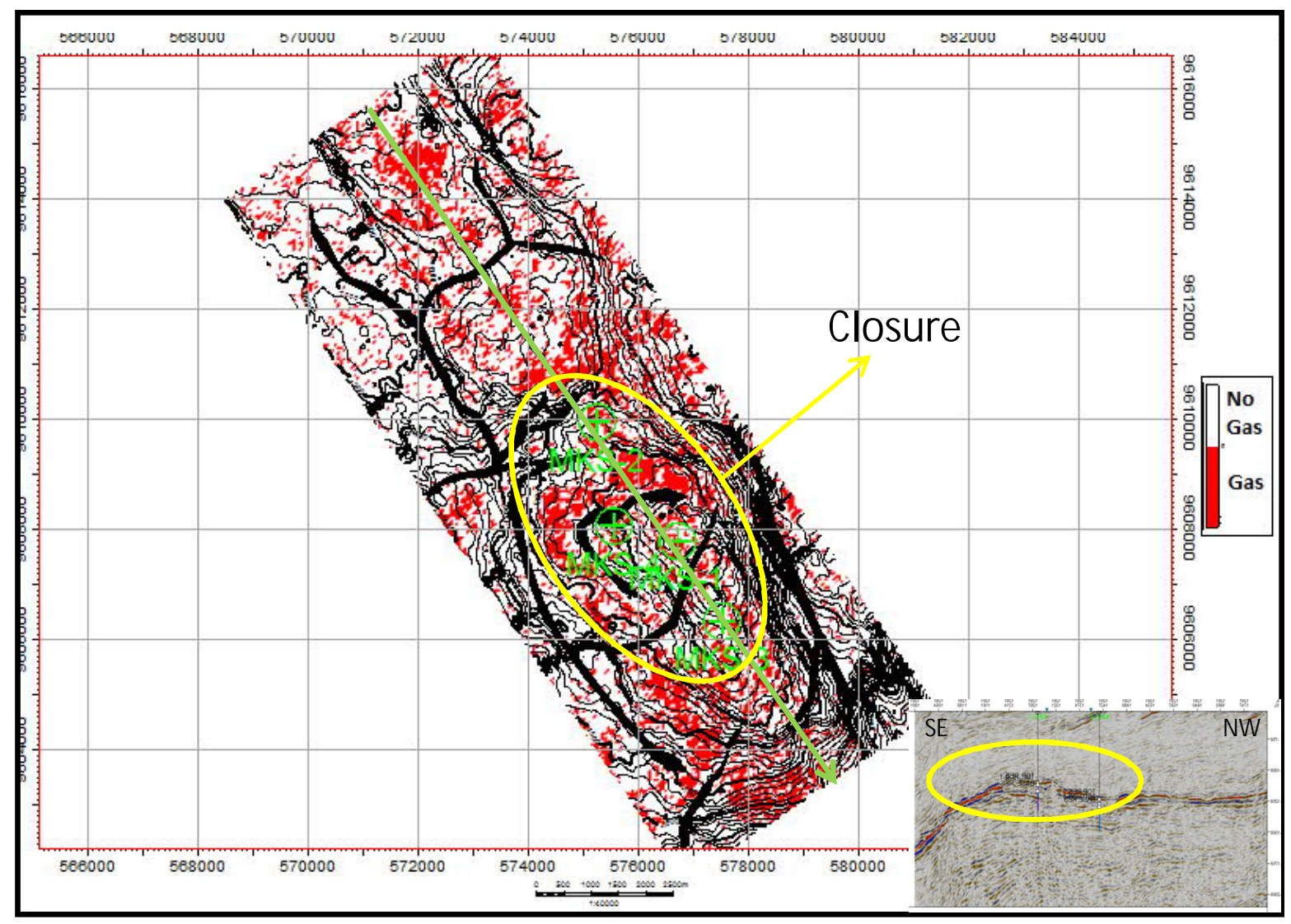

(b)

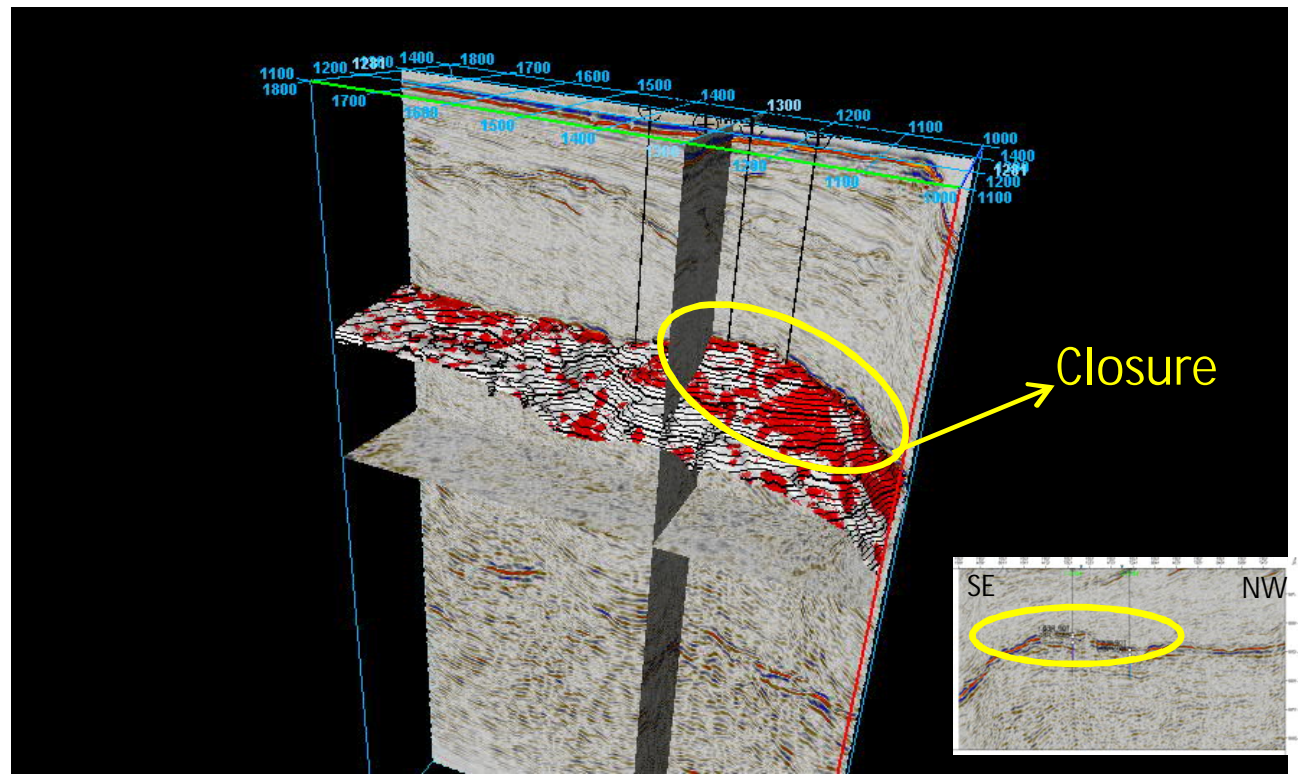

(c)

Gambar 5. (a) Penampang PDDF pada inline 1281. Warna merah diprediksi tersaturasi hidrokarbon. distribusi nilai PDDF pada peta time structure horizon TOP RES dengan tampilan top view (b) dan $3 D$ view (c). 